\title{
MONASHUniversity
}

Department of Econometrics and Business Statistics http://www.buseco.monash.edu.au/depts/ebs/pubs/wpapers/

\section{Modelling and forecasting}

\section{Australian domestic tourism}

George Athanasopoulos and Rob J Hyndman

October 2006

Working Paper 19/06 


\title{
Modelling and forecasting Australian domestic tourism
}

\author{
George Athanasopoulos \\ Department of Econometrics and Business Statistics, \\ Monash University, VIC 3800 \\ Australia. \\ Email: George.Athanasopoulos@buseco.monash.edu
}

\author{
Rob J Hyndman \\ Department of Econometrics and Business Statistics, \\ Monash University, VIC 3800 \\ Australia. \\ Email: Rob.Hyndman@buseco.monash.edu
}

17 October 2006

JEL classification: $\mathrm{C} 13, \mathrm{C} 22, \mathrm{C} 53$ 


\title{
Modelling and forecasting Australian domestic tourism
}

\begin{abstract}
In this paper, we model and forecast Australian domestic tourism demand. We use a regression framework to estimate important economic relationships for domestic tourism demand. We also identify the impact of world events such as the 2000 Sydney Olympics and the 2002 Bali bombings on Australian domestic tourism. To explore the time series nature of the data, we use innovation state space models to forecast the domestic tourism demand. Combining these two frameworks, we build innovation state space models with exogenous variables. These models are able to capture the time series dynamics in the data, as well as economic and other relationships. We show that these models outperform alternative approaches for short-term forecasting and also produce sensible long-term forecasts. The forecasts are compared with the official Australian government forecasts, which are found to be more optimistic than our forecasts.
\end{abstract}

Keywords: Australia, domestic tourism, exponential smoothing, forecasting, innovation state space models.

\section{Introduction}

The Australian tourism industry can be divided into three major segments: (i) international inbound tourism; (ii) domestic tourism; and (iii) outbound tourism. Of these, domestic tourism is the largest financial contributor to the Australian economy. In 2005, domestic tourism contributed an estimated $\$ 55.5$ billion to the Australian economy, more than three times the contribution of international arrivals (Tourism Forecasting Committee, 2005). Despite this, the main focus of Australian academic tourism research has been on international tourism (see, for example, Morris et al., 1995; Kulendran and King, 1997; Morley, 1998; Lim and McAleer, 2001, 2002; Kulendran and Witt, 2003); worldwide tourism research has had a similar focus (see Li et al. 2005 for a comprehensive survey).

Domestic tourism also plays a significant role in maintaining and improving tourism 
infrastructure, especially in regional Australia. An Australian tourist is much more likely than an international tourist to visit regional and remote areas of Australia that are not internationally promoted. Thus, Australian domestic tourism is an important topic that is in need of careful study and analysis.

To the best of our knowledge, the only forecasts available for the Australian domestic tourism market are those produced by the Tourism Forecasting Committee (TFC) and published by Tourism Research Australia (TRA). TRA is a business unit under the umbrella of Tourism Australia, which is an Australian federal government statutory authority. Tourism Australia was established after the initiatives of the Tourism White Paper (2003) which intended to strengthen the tourism industry.

Following the white paper, the TFC was also established as an independent body. The committee comprises experts from both the private and government sectors in the tourism and finance industry. Current members are: Tourism Australia, Australian Standing Committee on Tourism, Australian Tourism Export Council, Department of Industry Tourism and Resources, Australian Bankers Association, Tourism and Transport Forum Australia, Property Council of Australia (representing major property investors), Qantas and Queensland Tourism Industry Council. The TFC produces consensus forecasts for international, domestic and outbound tourism activity which are published by TRA. The forecasts produced by the TFC in October 2005 for the third quarter of 2005 and beyond show steady growth in the domestic market. In contrast, our forecasts show that the Australian domestic market is in decline, and it seems that it will remain this way at least in the short-term.

We develop three different statistical models for forecasting Australian domestic tourism. First, to help in understanding and capturing some of the economic relationships important to the domestic tourism market, we construct a regression model of tourism demand. This modelling framework identifies some useful economic relationships and significant events influencing the Australian domestic tourism market. However, as these models are static, they are unable to capture the dynamic properties of the data.

The second approach adopted is to use pure time series models to capture these dynamics. The models employed are single source of error (or innovation) state space models (see Aoki, 1987; Hannan and Deistler, 1988; Snyder, 1985; Ord et al., 1997; de Silva et al., 
2006). These have been extremely successful when applied to data from forecasting competitions (e.g., Hyndman et al., 2002; Makridakis et al., 1982; Makridakis and Hibon, 2000), and have numerous advantages over the more common form multiple source of error structural time series (STSM) models (as outlined in Ord et al. 2005). However, they have never previously been applied to tourism data.

The third modelling approach we take is to include exogenous variables in the innovation state space models. These models combine the advantages of each of the above modelling frameworks. Hence, they capture the significant economic relationships and events identified in the regression models, and combine these with the time series properties of the innovation state space models. Although other formulations of state space models with exogenous variables exist (see Harvey, 1990), this is the first time that the innovation state space formulation with exogenous variables has been published. A two-step estimation procedure is proposed. The estimated models produce accurate short term forecasts and sensible long term forecasts.

The data are introduced in Section 2. Section 3 describes the three models and compares them based on within-sample fits and out-of-sample forecast performance. The out-of-sample forecast evaluation also includes forecasts produced by the TFC. Section 4 presents and analyses the long-run forecasts from the three models and those from the TFC. We summarize our conclusions in Section 5.

\section{Data}

The Australian domestic tourism data were obtained from the National Visitor Survey, managed by TRA. Data is collected by computer-assisted telephone interviews from approximately 120,000 Australians aged 15 years and over on an annual basis (Tourism Reseach Australia 2005). We use the number of visitor nights (VN) as the indicator of tourism activity. We disaggregate the data based on the main purpose of travel: Holiday (Hol), Visiting Friends and Relatives (VFR), Business (Bus) and Other (Oth). The available sample spans from the 1st quarter of 1998 to the 2nd quarter of 2005. Hence, there are a total of $n=30$ quarterly observations (see Figure 1).

Figure 2 shows the total number of visitor nights (the aggregate of the series in 
Figure 1). Also shown are the forecasts produced for this series by the TFC in Tourism Forecasting Committee (2005). The annual TFC forecasts show a steady average growth of $0.9 \%$ per annum from 2006-2014. In contrast, there is no noticeable trend in the historical data from 1998-2005.

\section{Statistical models}

\subsection{Regression models}

The proposed tourism demand function is:

$$
V N_{t}^{i}=f\left(t, D E B T_{t}, D P I_{t}, G D P_{t}, B A L I_{t}, O L Y M P_{t}, M A R_{t}, J U N_{t}, S E P_{t}, \varepsilon_{t}\right)
$$

where $i=\{H o l, V F R, B u s, O t h\}, V N_{t}^{i}$ is the number of visitor nights per capita travelling for purpose $i, D E B T_{t}$ is real personal debt (by all lenders) per capita, $D P I_{t}$ is the price index for domestic holiday travel and accommodation, $G D P_{t}$ is the real gross domestic
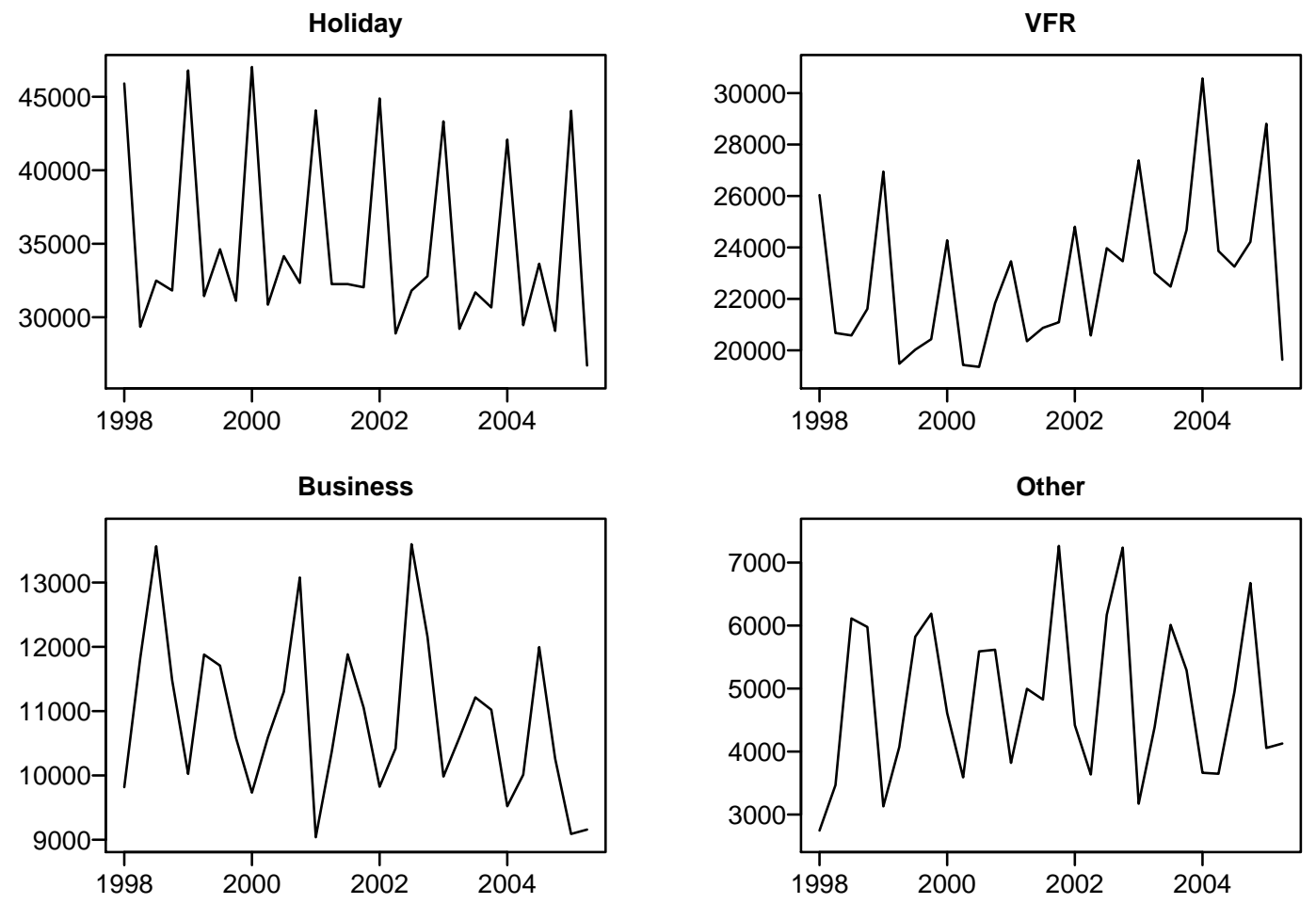

Figure 1: Quarterly observations for Australian domestic tourism: visitor nights (VN). 


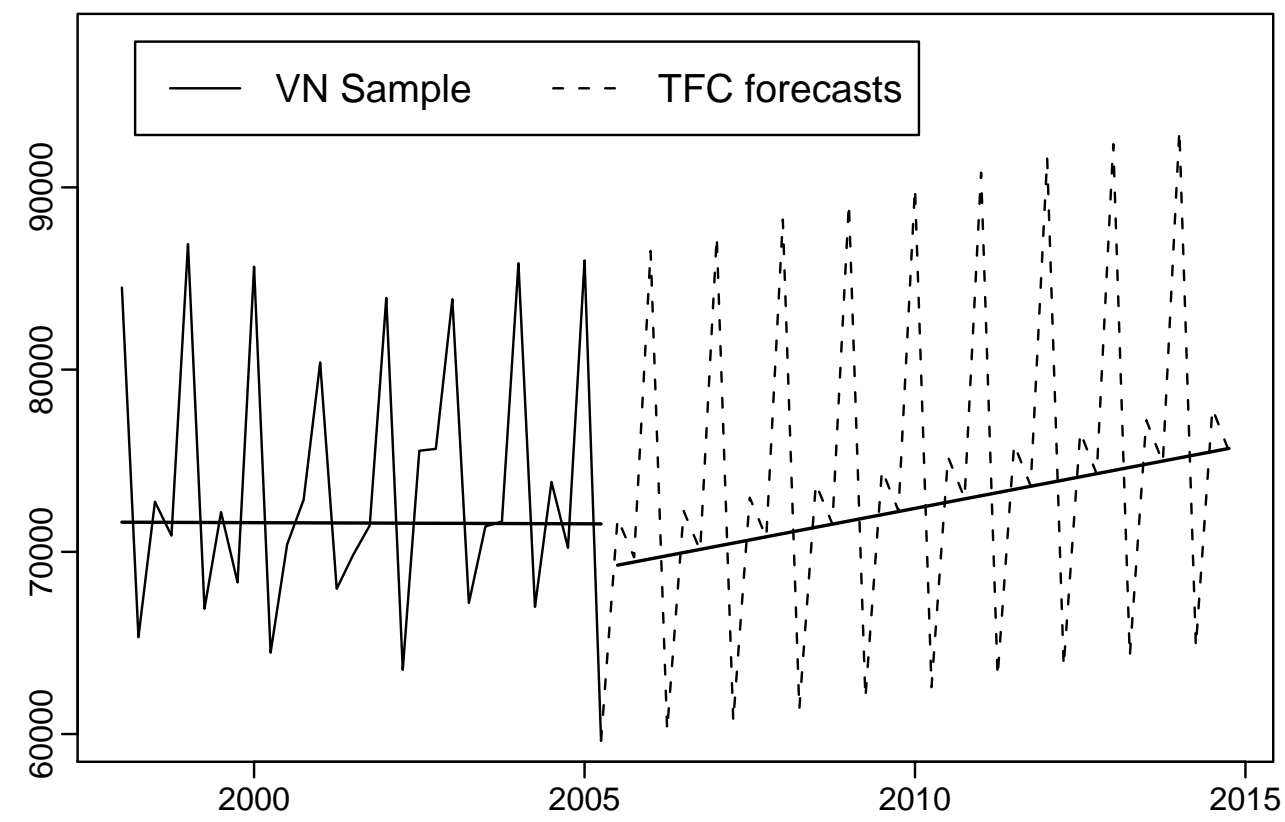

Figure 2: Linear trend lines fitted to the sample of total visitor nights and the TFC forecasts.

product per capita, $B A L I_{t}$ is a dummy variable capturing the effect of the bombings in Bali $\left(B A L I_{t}=1\right.$ during the 4 th quarter of 2002 and beyond), OLYMP $P_{t}$ is a dummy variable capturing the effect of the Sydney 2000 Olympic games $\left(O L Y M P_{t}=1\right.$ in the 4 th quarter of 2000, which is the quarter following the games, and 0 otherwise), $M A R_{t}, J U N_{t}$ and $S E P_{t}$ are seasonal dummy variables, and $\varepsilon_{t}$ is a random error term. The function $f$ is assumed to be linear. Full descriptions of the data, the data sources and projections of the regressors used for forecasting are provided in Appendix A.

We considered many other economic variables of interest including petrol prices, prices of competing goods (e.g., car sales), audio equipment and others. However, due to the small sample size and the lack of variation in many of these variables, they were found to be statistically insignificant. The small sample size also prevented us testing for nonlinear relationships such as threshold effects for the variables of interest.

Visual inspection of the dependent variables (see Appendix B for plots of the per capita data) suggests that stationarity tests are required. Table 1 presents the results from three unit root tests: the Augmented Dickey Fuller (ADF) test (Dickey and Fuller, 1979, 1981), 
the KPSS test (Kwiatkowski et al., 1992) and the Modified Phillips-Perron $\left(\mathrm{MZ}_{a}\right)$ test due to Ng and Perron (2001). Ng and Perron (2001) consider modified versions of four existing unit root tests. Their Monte-Carlo simulation results indicate that these tests have superior size and power to any existing test. The results presented here are robust to the choice of the test. In general, the hypothesis testing framework for unit roots can be simply presented by considering an autoregressive process such as:

$$
y_{t}=\rho y_{t-1}+\boldsymbol{z}_{t}^{\prime} \boldsymbol{\delta}+\varepsilon_{t}
$$

where $z_{t}$ is a set of exogenous regressors which may contain a constant and a time trend. In the $\mathrm{ADF}$ and $\mathrm{MZ}_{a}$ tests, the null hypothesis is that the series contains a unit root (i.e., $H_{0}:|\rho|=1$ versus $\left.H_{1}:|\rho|<1\right)$. The KPSS tests the null hypothesis that the series does not contain a unit root (i.e., $H_{0}:|\rho|<1$ versus $H_{1}: \rho=1$ ). Before applying these tests, each series was seasonally adjusted (see Figure 3) using an additive moving average method (e.g., Makridakis et al., 1998). The test results presented in Table 1 indicate that none of the four series contains a unit root.

Table 1: Unit root tests. The data generating processes assumed for $\ln V N_{t}^{H o l}$ and $\ln V N_{t}^{B u s}$ contain both an intercept and a deterministic trend. The data generating processes assumed for $\ln V N_{t}^{V F R}$ and $\ln V N_{t}^{\text {Oth }}$ contain only an intercept.

\begin{tabular}{llll}
\hline Seasonally adjusted series & ADF & KPSS & MZ $_{a}$ \\
\hline $\ln V N_{t}^{H o l}$ & $-5.44^{*}$ & $0.13^{*}$ & $-14.88^{\sharp}$ \\
$\ln V N_{t}^{V F R}$ & -2.47 & $0.22^{*}$ & $-10.98^{*}$ \\
$\ln V N_{t}^{\text {Bus }}$ & $-4.97^{*}$ & $0.10^{*}$ & $-16.47^{\sharp}$ \\
$\ln V N_{t}^{\text {Oth }}$ & $-6.43^{*}$ & $0.14^{*}$ & $-8.14^{*}$
\end{tabular}

* The test finds no unit root at the $5 \%$ level of significance.

$\sharp$ The test finds no unit root at the $10 \%$ level of significance.

However, at least two of the response variables are clearly trending (this is especially apparent in Figure 3 where the seasonal variation has been removed). Consequently, a deterministic trend and the growth rates of the explanatory variables are employed in the regression model; the growth rates are calculated as $(100 \times \Delta \ln (Z))$ for variable $Z$. We also include up to one lag of each regressor. After eliminating variables found to 

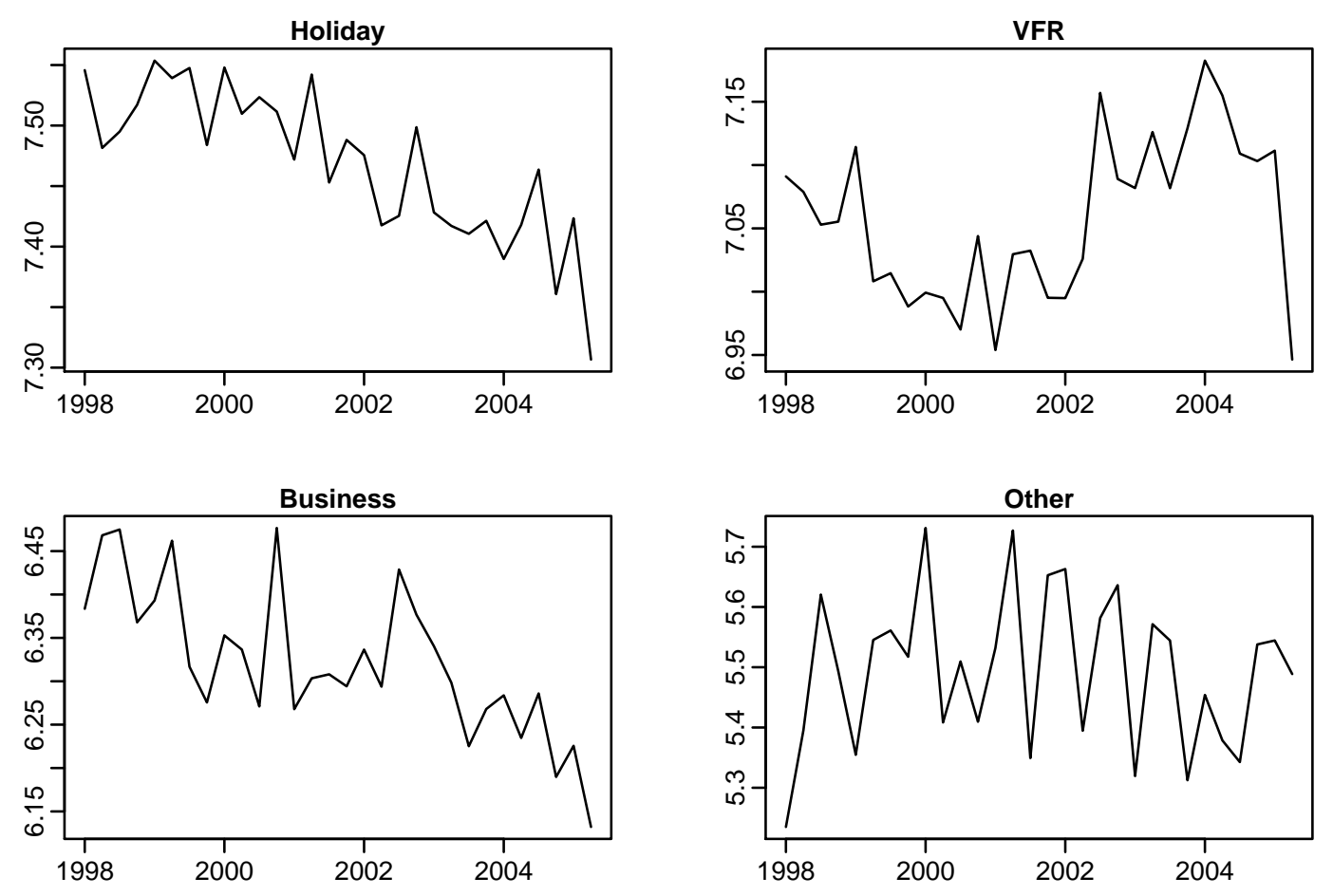

Figure 3: Seasonally adjusted natural logarithms of visitor nights per capita, i.e., seasonally adjusted $\ln V N_{t}^{i}$ 
be statistically insignificant at a $10 \%$ level of significance across all four equations, the general demand model employed is

$$
\begin{aligned}
1000 \ln V N_{t}^{i}= & c+\delta t+\beta_{1} D_{t-1}+\beta_{2} P_{t-1}+\beta_{3} Y_{t}+\beta_{4} B A L I_{t}+\beta_{5} O L Y M P_{t} \\
& +s_{1} M A R_{t}+s_{2} J U N_{t}+s_{3} S E P_{t}+\varepsilon_{t}
\end{aligned}
$$

where $D_{t-1}$ is the lag of the growth rate of $D E B T_{t} ; P_{t-1}$ is the lag of the growth rate of $D P I_{t} ; Y_{t}$ is the growth rate of $G D P_{t}$; and the remaining variables are as described in equation (1). The response variable was scaled up by 1000 to avoid very small estimated coefficients.

Table 2 shows the demand equations estimated one at a time using ordinary least squares (OLS). In this setting, the OLS estimator is equivalent to the generalised least squares (GLS) estimator employed in a seemingly unrelated regression (SUR) framework, as the equations contain identical regressors (refer to Green 2000, p.616, for proof). The equations show a satisfactory fit with $R^{2}$ values ranging from 0.82 for the "Other" variable to 0.98 for the "Holiday" variable. The diagnostic tests at the bottom of the table show that the residuals of each equation satisfy the basic OLS assumptions of no serial correlation, homoscedasticity and normality. Also the RESET test results indicate that the model is appropriately specified.

We simplified the models by eliminating insignificant variables one at a time, selecting the coefficient with the highest $\mathrm{p}$-value among all insignificant coefficients at the $5 \%$ level of significance. Then, because we expect that the errors across equations will be contemporaneously correlated and because not all equations include the same regressors, the system was estimated efficiently using the SUR estimation method (Zellner, 1963). The estimation results are presented in Table 3.

The estimated coefficient for the exponential trend is negative and statistically significant in the "Holiday" and "Business" equations. Hence, these results show a significant long term decline in visitor nights per capita where travel is for holiday and business purposes.

The estimated coefficient of the lag of the growth of DEBT is positive and statistically significant in the "Holiday" and "Business" equations. This variable can be considered a 
Table 2: Estimated coefficients of the unrestricted demand model of equation (3). Standard errors are shown in parentheses beneath each coefficient.

\begin{tabular}{|c|c|c|c|c|}
\hline Regressor & Holiday & VFR & Business & Other \\
\hline Intercept & $\begin{array}{c}7493.33^{*} \\
(16.71)\end{array}$ & $\begin{array}{c}7041.23^{*} \\
(34.61)\end{array}$ & $\begin{array}{c}6472.51^{*} \\
(30.39)\end{array}$ & $\begin{array}{c}5823.92^{*} \\
(80.78)\end{array}$ \\
\hline$t$ & $\begin{array}{c}-5.14^{*} \\
(0.91)\end{array}$ & $\begin{array}{c}-2.21 \\
(1.88)\end{array}$ & $\begin{array}{c}-8.04^{*} \\
(1.65)\end{array}$ & $\begin{array}{l}6.04 \\
(4.38)\end{array}$ \\
\hline$D_{t-1}$ & $\begin{array}{l}4.34^{*} \\
(1.30)\end{array}$ & $\begin{array}{l}4.84^{\sharp} \\
(2.70)\end{array}$ & $\begin{array}{l}7.88^{*} \\
(2.37)\end{array}$ & $\begin{array}{c}-3.88 \\
(6.29)\end{array}$ \\
\hline$P_{t-1}$ & $\begin{array}{l}-5.45^{*} \\
(1.88)\end{array}$ & $\begin{array}{l}1.81 \\
(3.89)\end{array}$ & $\begin{array}{l}8.04^{*} \\
(3.42)\end{array}$ & $\begin{array}{c}-5.89 \\
(9.08)\end{array}$ \\
\hline$Y_{t}$ & $\begin{array}{c}-39.09^{*} \\
(9.61)\end{array}$ & $\begin{array}{c}-14.80 \\
(19.91)\end{array}$ & $\begin{array}{c}-21.10 \\
(17.48)\end{array}$ & $\begin{array}{c}-67.23 \\
(46.48)\end{array}$ \\
\hline$B A L I_{t}$ & $\begin{array}{c}-14.20 \\
(16.31)\end{array}$ & $\begin{array}{c}108.02^{*} \\
(33.80)\end{array}$ & $\begin{array}{l}35.70 \\
(29.67)\end{array}$ & $\begin{array}{c}-168.23^{*} \\
(78.88)\end{array}$ \\
\hline$O L Y M P_{t}$ & $\begin{array}{l}31.60 \\
(38.99)\end{array}$ & $\begin{array}{l}26.78 \\
(80.77)\end{array}$ & $\underbrace{118.17^{\sharp}}_{(70.92)}$ & $\begin{array}{c}-292.65 \\
(188.52)\end{array}$ \\
\hline$M A R_{t}$ & $\begin{array}{l}342.68^{*} \\
(13.40)\end{array}$ & $\begin{array}{c}156.95^{*} \\
(27.76)\end{array}$ & $\begin{array}{l}-180.97^{*} \\
(24.37)\end{array}$ & $\begin{array}{c}-563.63^{*} \\
(64.79)\end{array}$ \\
\hline$J U N_{t}$ & $\begin{array}{c}-39.62^{*} \\
(13.52)\end{array}$ & $\begin{array}{c}-56.84^{*} \\
(28.01)\end{array}$ & $\begin{array}{c}-40.34 \\
(24.59)\end{array}$ & $\begin{array}{c}-510.12^{*} \\
(65.37)\end{array}$ \\
\hline$S E P_{t}$ & $\begin{array}{l}31.13^{*} \\
(14.35)\end{array}$ & $\begin{array}{c}-48.22 \\
(29.74)\end{array}$ & $\begin{array}{l}46.07 \sharp \\
(26.11)\end{array}$ & $\begin{array}{c}-141.28^{*} \\
(69.41)\end{array}$ \\
\hline$R^{2}$ & 0.98 & 0.82 & 0.88 & 0.82 \\
\hline $\bar{R}^{2}$ & 0.97 & 0.75 & 0.82 & 0.73 \\
\hline$Q N^{a}$ & 0.23 & 0.40 & 0.57 & 1.07 \\
\hline$Q S C_{\text {lags }}^{b}$ & $1.12_{2}$ & $2.09_{2}$ & $4.97_{2}$ & $9.61_{3}^{b}$ \\
\hline$Q H T^{c}$ & 11.27 & 15.65 & 15.34 & 7.71 \\
\hline$Q R R^{d}$ & 0.51 & 1.19 & 1.76 & 1.76 \\
\hline \multicolumn{5}{|c|}{$\begin{array}{l}\bar{a} \text { Jarque and Bera (1980) } \chi^{2} \text { test for normality. } \\
b \text { Breusch (1978) and Godfrey (1978) Lagrange multiplier } \chi^{2} \text { test for serial } \\
\text { correlation. } \\
{ }^{c} \text { White (1980) } \chi^{2} \text { test for heteroscedasticity. } \\
{ }^{d} \text { Ramsey (1969) RESET } \chi^{2} \text { test for misspecification. } \\
{ }^{*} \text { Significant at the } 5 \% \text { level. } \\
\sharp \text { Significant at the } 10 \% \text { level. } \\
{ }^{b} \text { These residuals showed some weak third order serial correlation which was ignored. }\end{array}$} \\
\hline
\end{tabular}

proxy for consumer confidence. An increase in the growth rate of borrowing in the last quarter (i.e., a rapid growth in consumer confidence in the previous quarter), results in an increase in domestic travel for both "Holiday" and "Business" purposes.

The lag of the growth in the domestic travel price index, DPI, has mixed results across equations. In the "Holiday" equation, the coefficient of DPI is negative and statistically significant. This suggests that as prices for domestic travel grew faster (or declined more 
Table 3: Estimated coefficients of the demand model of equation (3) after eliminating insignificant parameters. Standard errors are shown in parentheses beneath each coefficient.

\begin{tabular}{|c|c|c|c|c|}
\hline Regressor & Holiday & VFR & Business & Other \\
\hline Intercept & $\begin{array}{c}7505.57^{*} \\
(13.33)\end{array}$ & $\begin{array}{c}7020.25^{*} \\
(21.03)\end{array}$ & $\begin{array}{c}6441.09^{*} \\
(22.84)\end{array}$ & $\begin{array}{c}5771.92^{*} \\
(47.28)\end{array}$ \\
\hline$t$ & $\begin{array}{c}-5.91^{*} \\
(0.50)\end{array}$ & & $\begin{array}{c}-6.17^{*} \\
(0.88)\end{array}$ & \\
\hline$D_{t-1}$ & $\begin{array}{l}4.41^{*} \\
(1.23)\end{array}$ & & $\begin{array}{l}5.91^{*} \\
(2.00)\end{array}$ & \\
\hline$P_{t-1}$ & $\begin{array}{c}-4.11^{*} \\
(1.64)\end{array}$ & & $\begin{array}{l}7.58^{*} \\
(2.89)\end{array}$ & \\
\hline$Y_{t}$ & $\begin{array}{c}-43.71^{*} \\
(8.14)\end{array}$ & & & \\
\hline$B A L I_{t}$ & & $\begin{array}{l}56.61^{*} \\
(17.75)\end{array}$ & & \\
\hline$O L Y M P_{t}$ & & & $\begin{array}{c}148.00^{*} \\
(51.26)\end{array}$ & \\
\hline$M A R_{t}$ & $\begin{array}{c}338.09^{*} \\
(13.06)\end{array}$ & $\underbrace{170.33^{*}}_{(26.87)}$ & $\begin{array}{c}-170.83^{*} \\
(24.28)\end{array}$ & $\begin{array}{c}-540.23^{*} \\
(64.74)\end{array}$ \\
\hline$J U N_{t}$ & $\begin{array}{c}-43.19^{*} \\
(12.40)\end{array}$ & $\frac{-71.36^{*}}{(26.87)}$ & $\begin{array}{c}-42.57 \sharp \\
(24.51)\end{array}$ & $\begin{array}{c}-460.75^{*} \\
(64.74)\end{array}$ \\
\hline$S E P_{t}$ & $\begin{array}{l}27.78^{\sharp} \\
(14.01)\end{array}$ & $\begin{array}{c}-33.73 \\
(27.84)\end{array}$ & $\begin{array}{c}55.03^{*} \\
(25.57) \\
\end{array}$ & $\begin{array}{c}-109.13 \\
(66.86)\end{array}$ \\
\hline$R^{2}$ & 0.98 & 0.79 & 0.86 & 0.77 \\
\hline $\bar{R}^{2}$ & 0.98 & 0.75 & 0.82 & 0.74 \\
\hline
\end{tabular}

slowly) in the previous quarter, domestic holiday travel decreased. However, the coefficient in the "Business" equation is positive and statistically significant. This may suggest that domestic travel prices have been driven up by an increase in economic activity. An increase in economic activity should also result in an increase in domestic travel for business purposes, leading to the positive relationship between the lag of the growth rate of DPI and business travel.

The coefficient of GDP growth was found to be negative across all equations, but was only statistically significant in the "Holiday" equation. The negative coefficient suggests that an increase in the growth of GDP results in a significant decline in visitor nights for holiday purposes, and vice versa. Perhaps the explanation for this is that during periods of increasing economic activity, domestic holiday travel decreases significantly as Australians choose to travel to overseas destinations instead. Tourism Forecasting Committee (2005) shows that for Australian residents, short-term 
departures to overseas destinations have grown at approximately $4 \%$ per annum on average between 1995 and 2004.

The dummy variable for the Sydney Olympics captures a positive and statistically significant increase of business travel in the December quarter of 2000. This is the quarter following the Sydney Olympic games, which suggests that business travel was put on hold for the Olympic games and took place immediately afterwards.

The dummy variable for the Bali 2002 bombings captures a positive and statistically significant mean shift in the VFR series. After the Bali bombings, Australians reverted to visiting friends and relatives more than before.

The coefficient estimates for the seasonal dummy variables are consistent with what would be expected for Australian domestic travel. The March quarter has the highest holiday and VFR travel, but the lowest business travel. This is the summer quarter for Australia and includes the longest period of school holidays. The lowest level of holiday and VFR travel is found in the June quarter which includes the first semester of all levels of schooling.

\subsection{Exponential smoothing via innovation state space models}

Exponential smoothing was proposed in the late 1950s (see the pioneering works of Brown 1959, Holt 1957 and Winters 1960) and has motivated some of the most successful forecasting methods. Forecasts produced using exponential smoothing methods are weighted averages of past observations, with the weights decaying exponentially as the observations get older. In other words, the more recent the observation the higher the associated weight.

Recently, a statistical framework for these forecasting methods has been developed (Ord et al., 1997; Hyndman et al., 2002). Innovation state space models encapsulate the notion of exponential smoothing in a state space framework, and allow maximum likelihood estimation, model selection and prediction intervals to be derived.

Exponential smoothing methods have been applied to tourism demand (see González and Moral, 1995; Turner and Witt, 2001; Cho, 2003; du Preez and Witt, 2003) 
through the framework of structural time series models (Harvey, 1990) which give approximately the same forecasts. Innovation state space models involve only a single source of error. The optimal forecasts from an innovation state space model are identical to those obtained using exponential smoothing methods (Hyndman et al., 2005).

The modelling strategy followed in this paper is a restricted version of the Hyndman et al. (2002) methodology for innovation state space models, which is based on the taxonomy proposed by Pegels (1969), extended by Gardner (1985) and advocated by Makridakis et al. (1998). In this study, only additive models are considered. Given that all series have a pronounced seasonal component, the models considered are listed in Table 4. All three models have additive errors and an additive seasonal component and may contain no trend, an additive trend or a damped trend. We refer to this class of models as "ETS" (for Error-Trend-Seasonal) models. The damped trend model was proposed by Gardner and McKenzie (1985) as a modification to Holt's linear model. This modification comes through the parameter $\phi$ which dampens the trend. When $0<\phi<1$, the forecasts produced by the model converge to $l_{n}+b_{n} /(1-\phi)$ as $h \rightarrow \infty$. Thus, the short-run forecasts are trended but the long-run forecasts are constant.

Table 4: Innovation state space additive models with seasonal component

\begin{tabular}{lll}
\hline No trend & Additive trend & Damped trend \\
\hline$y_{t}=l_{t-1}+s_{t-m}+\varepsilon_{t}$ & $y_{t}=l_{t-1}+b_{t-1}+s_{t-m}+\varepsilon_{t}$ & $y_{t}=l_{t-1}+b_{t-1}+s_{t-m}+\varepsilon_{t}$ \\
$l_{t}=l_{t-1}+\alpha \varepsilon_{t}$ & $l_{t}=l_{t-1}+b_{t-1}+\alpha \varepsilon_{t}$ & $l_{t}=l_{t-1}+b_{t-1}+\alpha \varepsilon_{t}$ \\
$s_{t}=s_{t-m}+\gamma \varepsilon_{t}$ & $b_{t}=b_{t-1}+\beta \varepsilon_{t}$ & $b_{t}=\phi b_{t-1}+\beta \varepsilon_{t}$ \\
& $s_{t}=s_{t-m}+\gamma \varepsilon_{t}$ & $s_{t}=s_{t-m}+\gamma \varepsilon_{t}$ \\
& $\hat{y}_{n+h}=l_{n}+h b_{n}+s_{n+h-m}$ & $\hat{y}_{n+h}=l_{n}+\left(1+\phi+\cdots+\phi^{h-1}\right) b_{n}$ \\
$\hat{y}_{n+h}=l_{n}+s_{n+h-m}$ & & $+s_{n+h-m}$ \\
& & \\
\hline
\end{tabular}

$l_{t}$ denotes the level of the series at time $t ; b_{t}$ denotes the slope at time $t ; s_{t}$ denotes the seasonal component at time $t ; m$ is the number of seasons in a year; $\hat{y}_{n+h}$ is the $h$ step ahead out of sample forecast value.

Treating this as a time series modelling exercise, the dependent variable considered is visitor nights instead of visitor nights per capita. The parameters are restricted to $0<$ $\alpha<1,0<\beta<\alpha, 0<\gamma<1$ and $0<\phi<0.98$. The damping parameter $\phi$ is restricted to a maximum of 0.98 to ensure that the damped model gives noticeably different forecasts from the additive trend model. Section 3.3 includes further discussion on the damped trend model. 
The models are estimated by maximising the likelihood function using the $\mathrm{R}$ package "forecast" (Hyndman, 2006), and the Akaike Information Criterion (AIC) is employed as the model selection criterion. The Bayesian Information Criterion (BIC) was also considered but was found to be too restrictive. The selected models and estimated coefficients are presented in Table 5. The model selected for the "Holiday", "Business" and "Other" series is the damped trend model, while a no-trend model is selected for VFR. The seasonal smoothing parameter, $\gamma$, is zero for all models, indicating a fixed and unchanging seasonal pattern.

Table 5: Models and estimated parameters

\begin{tabular}{ccccc}
\hline \multirow{2}{*}{$\begin{array}{c}\text { Model } \\
\text { Parameter }\end{array}$} & Holiday & VFR & Business & Other \\
\cline { 2 - 5 } & Damped trend & No trend & Damped trend & Damped trend \\
\hline$\alpha$ & 0.10 & 0.52 & 0.00 & 0.00 \\
$\beta$ & 0.08 & & 0.00 & 0.00 \\
$\gamma$ & 0.00 & 0.00 & 0.00 & 0.00 \\
$\phi$ & 0.85 & & 0.98 & 0.34 \\
\hline
\end{tabular}

\subsection{Innovation state space models with exogenous variables}

The two modelling approaches described so far have contrasting advantages and disadvantages. The regression models identified some very useful economic relationships, such as the positive relationship between consumer confidence and domestic holiday travel. The effects of significant world events such as the Sydney Olympic games and the Bali bombings were also highlighted. These relationships are important to policy makers (such as Tourism Australia). However, the regression model does have some disadvantages. For example, if the model is used for forecasting, forecasts of the regressors are required. Furthermore, the regression model is static-it does not explore the dynamic properties of the data. In contrast, time series models such as the ETS capture the dynamic characteristics of the data and use these to forecast the future.

In this section, a combination of these two modelling strategies is proposed, giving ETS models with exogenous variables or "ETSX" models. These models are estimated via a two-step procedure. First, we identify the exogenous variables to be included in the model. These are the variables found to be statistically significant for each equation in 
the SUR estimation results, as presented in Table 3. In the second step, the fully specified model is estimated by maximising the likelihood function.

The dependent variable employed is visitor nights per capita, i.e., $y_{t}$ is $V N_{t}^{i}$ as defined in equation (1). Because the seasonal component in each of the time series models was deterministic, we model seasonality using seasonal dummies in the set of exogenous variables.

A damped trend model is used for all series. Including the exogenous variables in the observation equation, the ETSX model is

$$
\begin{aligned}
y_{t} & =l_{t-1}+b_{t-1}+\boldsymbol{z}_{t}^{\prime} \boldsymbol{\delta}+\varepsilon_{t} \\
l_{t} & =l_{t-1}+b_{t-1}+\alpha \varepsilon_{t} \\
b_{t} & =\phi b_{t-1}+\beta \varepsilon_{t} \\
\hat{y}_{n+h} & =l_{n}+\left(1+\phi+\cdots+\phi^{h-1}\right) b_{n}+\hat{\boldsymbol{z}}_{n+h}^{\prime} \hat{\boldsymbol{\delta}}
\end{aligned}
$$

where $z_{t}$ is a vector of the exogenous variables not including the constant and the time trend. When $0<\phi<1$, the forecasts produced by model (5) converge to $l_{n}+b_{n} /(1-\phi)+\hat{\boldsymbol{z}}_{n+h}^{\prime} \hat{\boldsymbol{\delta}}$ as $h \rightarrow \infty$. Thus, the short-term forecasts produced by this model are largely affected by the final trend estimate $b_{n}$. However, as we forecast further into the future, this effect diminishes (i.e., the trend is damped). This allows long-term forecasts to be largely driven by the forecasts of the exogenous variables. This type of model has important policy implications as long-term forecasts (in this case tourism demand) can reflect the beliefs/views of policy makers about the future of the exogenous variables.

The estimated models are presented in Table 6 . The smoothing parameters are restricted as in Section 3.2. The estimates of the coefficients of the exogenous variables seem to be consistent with the corresponding estimates in the regression framework of Section 3.1.

\subsection{In-sample evaluation of the three models}

We evaluate how well the three models fit the data by computing some in-sample accuracy measures. The accuracy measures employed are the root mean squared error 
Table 6: Estimates of the ETSX models

\begin{tabular}{lrrrr}
\hline Parameter & Holiday & VFR & Business & Other \\
\hline$\alpha$ & 0.13 & 0.00 & 0.47 & 0.01 \\
$\beta$ & 0.01 & 0.00 & 0.00 & 0.00 \\
$\phi$ & 0.98 & 0.97 & 0.98 & 0.76 \\
\hline Variable & & & & \\
$Y_{t}$ & -67.67 & & & \\
$D_{t-1}$ & 6.79 & & 3.78 & \\
$P_{t-1}$ & -7.25 & & 4.21 & \\
BALI $_{\text {OLYMP }}$ & & 132.09 & & \\
$M A R_{t}$ & & & 104.05 & \\
$J U N_{t}$ & 661.69 & 213.54 & -95.78 & -129.18 \\
SEP $_{t}$ & -65.52 & -72.54 & -21.25 & -116.15 \\
\hline
\end{tabular}

Table 7: In-sample accuracy measures for the three models.

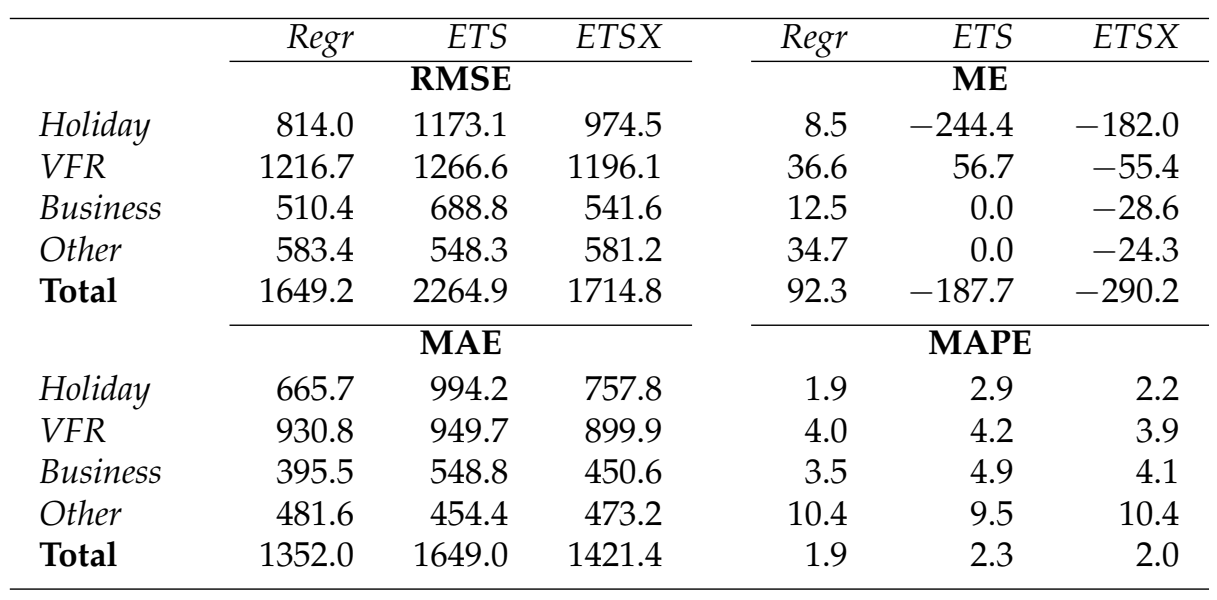

(RMSE), the mean error $(M E)$, the mean absolute error $(M A E)$ and the mean absolute percentage error (MAPE) (see Makridakis et al. 1998 for definitions). The results are presented in Table 7.

For each error measure, the first four rows summarize the error produced by each of the three models when fitted to the individual series. The final row labelled "Total" summarizes the aggregated errors produced by each model for the total of visitor nights. The mean error provides a measure of the bias in the fitted models, and the other three measures describe the accuracy of the models in fitting the data.

Let us concentrate on the MAPE results presented on the lower right corner of the table. 
The regression model provides the best fit for the "Holiday" and "Business" series. For these cases the regression model included a deterministic trend. The fit of the ETSX models approached the fit of the regression models as the damping parameter $\phi$ approached one. For the "VFR" case, where no deterministic trend was included in the regression model, the fit of the ETSX model was best. In the case of the "Other" series the ETS model performed best. This is not surprising because this series is the most difficult to model via economic relationships as it contains travel for very diverse purposes.

\subsection{Forecast evaluation of the three models and TFC}

The in-sample evaluation of the models has shown that the models fit the data quite well. Although this is useful when modelling domestic tourism, it does not mean that the models can forecast well. In order to get some indication of the forecasting performance of the models, we also conduct an out-of-sample forecast performance evaluation.

Due to the short sample size available, the period September 2004 to June 2005 is selected as the "holdout" sample. Thus, the models are estimated using the first 26 observations (March 1998 to June 2004) and 1-4 step-ahead forecasts are produced.

The forecast error measures are presented in Table 8. For each measure, the first four rows show the error produced by each model for each individual series. The "Total" row gives the forecast error produced by each model for the total aggregate of visitor nights. The final "Average" row gives the error of each model, averaged across the four individual series.

Again, we will focus on the most popular forecast error measure, the MAPE, presented in the lower right corner of Table 8. The three models developed in this study seem to be competitive in forecasting the individual series. Forecasting the total visitor nights, the ETSX models perform best producing the lowest MAPE of $4.20 \%$.

There is only one instance where the TFC forecasts outperform any of the models. This is for the "Business" series where the TFC forecasts outperform the ETS model. The average improvement that can be achieved by tourism analysts in implementing our ideas is highlighted in the "Average" row. Here the TFC average MAPE is between 60 and 70\% larger than that for any of our models. 
Table 8: Forecast error measures calculated for the holdout sample: September 2004 to June 2005

\begin{tabular}{|c|c|c|c|c|c|c|c|c|}
\hline & $\operatorname{Regr}$ & ETS & ETSX & TFC & Regr & ETS & ETSX & TFC \\
\hline & \multicolumn{4}{|c|}{ RMSE } & \multicolumn{4}{|c|}{ ME } \\
\hline Holiday & 680.8 & 1633.1 & 1761.0 & 2255.6 & 185.8 & -383.7 & -71.7 & -286.1 \\
\hline$V F R$ & 1925.9 & 1625.4 & 1892.0 & 2449.9 & -919.5 & -422.4 & -1067.2 & -1718.9 \\
\hline Business & 1787.0 & 1081.5 & 857.7 & 748.2 & -363.4 & -919.3 & -612.6 & -397.0 \\
\hline Other & 535.4 & 468.5 & 536.0 & 1056.3 & -122.3 & -173.6 & -171.7 & 73.1 \\
\hline Total & 3746.6 & 3696.0 & 3826.7 & 4233.5 & -1219.5 & -1898.9 & -1923.1 & -2328.9 \\
\hline \multirow[t]{2}{*}{ Average } & 1232.3 & 1202.1 & 1261.7 & 1627.5 & -304.9 & -474.7 & -480.8 & -582.2 \\
\hline & \multicolumn{4}{|c|}{ MAE } & \multicolumn{4}{|c|}{ MAPE } \\
\hline Holiday & 1856.7 & 1426.8 & 1528.3 & 2186.1 & 5.8 & 4.8 & 5.0 & 7.0 \\
\hline$V F R$ & 954.2 & 1131.9 & 1118.8 & 1882.2 & 4.8 & 5.2 & 5.5 & 8.5 \\
\hline Business & 507.5 & 919.3 & 612.6 & 731.9 & 5.2 & 9.5 & 6.4 & 7.4 \\
\hline Other & 380.5 & 316.1 & 371.0 & 906.2 & 7.7 & 6.5 & 7.6 & 17.6 \\
\hline Total & 2960.5 & 2757.6 & 2657.6 & 3126.9 & 4.5 & 4.3 & 4.2 & 4.9 \\
\hline Average & 924.7 & 948.5 & 907.7 & 1426.6 & 5.9 & 6.5 & 6.1 & 10.1 \\
\hline
\end{tabular}

\section{Comparing long run forecasts from the three models and TFC}

Figure 4 plots the long term visitor nights forecasts (aggregated to annual), produced by each of the models. Also plotted are the forecasts produced by the TFC (Tourism Forecasting Committee, 2005). The annual percentage growth values in these forecasts are shown in Table 9. All three models predict an overall decrease in visitor nights for the year 2005. This is also predicted by the TFC. The largest decline is predicted by the ETS models (a drop of 3.74\% in comparison to 2004) followed by the TFC forecast (a drop of 3.27\%). However, from 2006, the forecasts produced by the models tell a very different story about the future of Australian domestic tourism compared to the TFC forecasts.

The regression model driven by deterministic trends (in the "Holiday" and "Business" series) predicts a continuous decline in visitor nights. The average predicted decline over the 2005-2014 period is $0.48 \%$ per annum. The rate of decline diminishes the further the forecasts are into the future, due to the nature of the exponential trend. If the forecast horizon was extended enough, one would see the forecasts approach an asymptote parallel to the horizontal axis. This is an important implication of the exponential (instead of linear) trend on the forecasts produced by these models. It shows that this type of model does not forecast negative visitor nights at some point in the future, as would be the case if a linear trend was employed. 


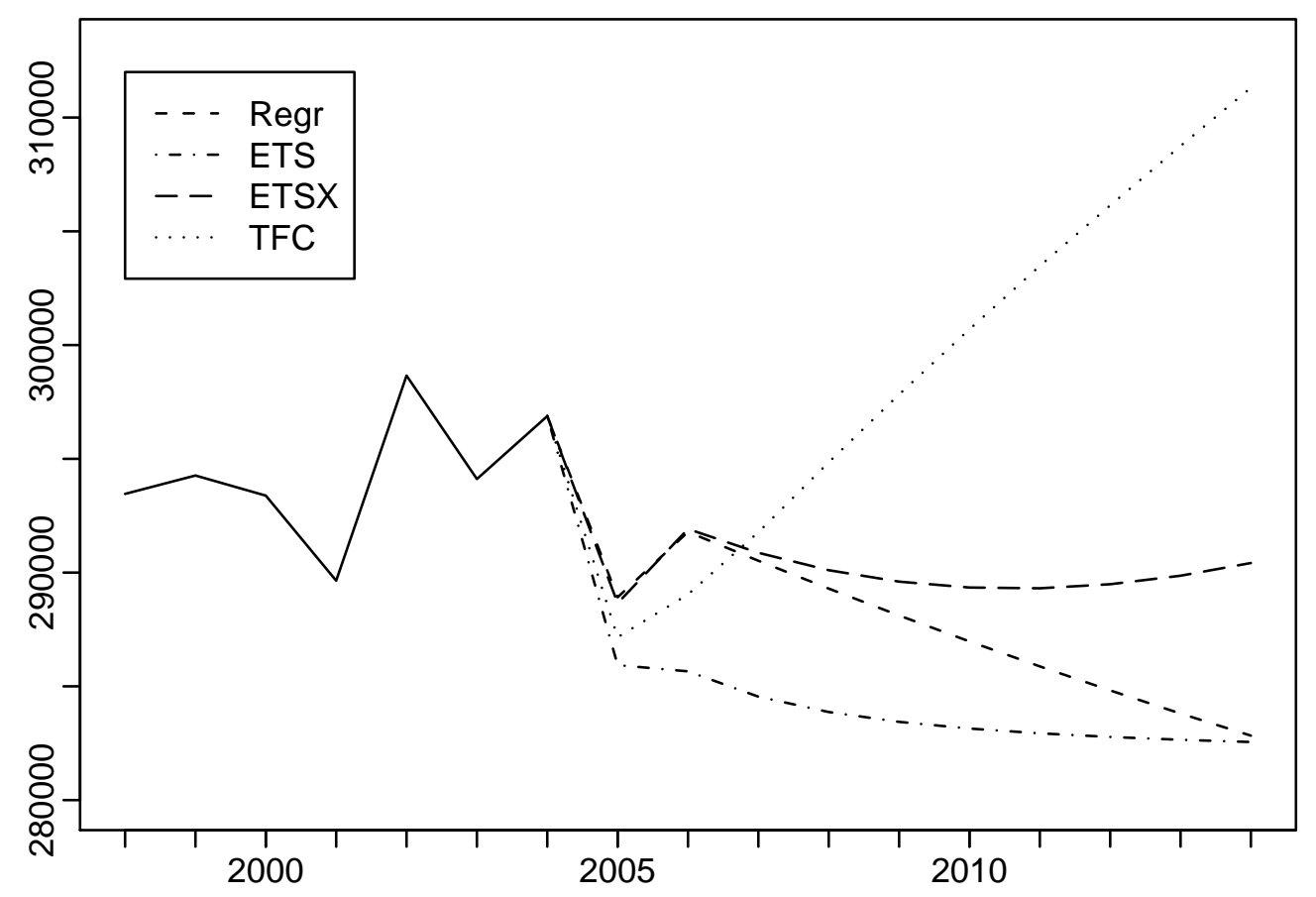

Figure 4: Long run annual forecasts for total visitor nights from the three models and the TFC.

The ETS models predict the lowest number of domestic visitor nights with not one increase for the period 2005-2014. Given that three of the series are modelled by a damped trend model the rate of decline is damped. The average percentage decrease in visitor nights over the period $2005-2014$ is $0.55 \%$. However, the average decrease for the period $2005-2008$ is $1.17 \%$ compared to $0.13 \%$ for the period $2009-2014$.

The most optimistic of our forecasts come from the ETSX models. Recall that these models are a combination of the ETS damped trend model and the exogenous variables. The characteristics of the forecast function of this model (discussed in Section 3.3) can be now seen in operation. From 2006 to 2011, the models predict a decline in the visitor nights, but this decline is rapidly damped. Beyond 2011, the trend is damped enough for the growth in the exogenous variables (such as the growth in the Australian population, the growth in GDP, etc.) to dominate and produce an overall growth in visitor nights. For the whole period 2005-2014 these models predict an average decline of $0.22 \%$.

In contrast to the forecasts from any of the three models, the TFC predict a steady growth in visitor nights for the period 2005-2014. The average predicted growth over 2005-2014 
Table 9: Percentage growth/decline in visitor nights from 1998 to 2014

\begin{tabular}{|c|c|c|c|c|c|}
\hline Period & Actual & Regr & ETS & ETSX & TFC \\
\hline 98-99 & 0.28 & & & & \\
\hline 99-00 & -0.30 & & & & \\
\hline 00-01 & -1.27 & & & & \\
\hline 01-02 & 3.11 & & & & \\
\hline $02-03$ & -1.52 & & & & \\
\hline 03-04 & 0.94 & & & & \\
\hline $04-05$ & & -2.68 & -3.74 & -2.77 & -3.27 \\
\hline 05-06 & & 0.99 & -0.19 & 1.13 & 0.66 \\
\hline $06-07$ & & -0.43 & -0.45 & -0.36 & 0.95 \\
\hline 07-08 & & -0.42 & -0.30 & -0.26 & 1.05 \\
\hline 08-09 & & -0.41 & -0.22 & -0.17 & 1.01 \\
\hline 09-10 & & -0.40 & -0.17 & -0.09 & 0.96 \\
\hline 10-11 & & -0.38 & -0.14 & -0.01 & 0.93 \\
\hline $11-12$ & & -0.37 & -0.12 & 0.06 & 0.88 \\
\hline $12-13$ & & -0.36 & -0.11 & 0.13 & 0.85 \\
\hline 13-14 & & -0.34 & -0.10 & 0.19 & 0.83 \\
\hline \multicolumn{6}{|c|}{ Average growth } \\
\hline 99-04 & 0.21 & & & & \\
\hline 05-10 & & -0.56 & -0.84 & -0.42 & 0.23 \\
\hline 05-14 & & -0.48 & -0.55 & -0.22 & 0.48 \\
\hline \multicolumn{6}{|c|}{ Total growth } \\
\hline 98-04 & 1.16 & & & & \\
\hline $04-10^{a}$ & & -3.34 & -5.01 & -2.54 & 1.29 \\
\hline $04-14^{a}$ & & -4.73 & -5.45 & -2.17 & 4.86 \\
\hline $05-14^{b}$ & & -2.11 & -1.78 & 0.61 & 8.41 \\
\hline
\end{tabular}

is $0.48 \%$. This means that domestic visitor nights are predicted to increase by $8.41 \%$ over the next ten years. This is a much greater total increase than predicted by any of the three statistical models. The regression and ETS models predict a total decline of $2.11 \%$ and $1.78 \%$ respectively. The ETSX models predict a small total growth of $0.61 \%$.

Figure 5 presents the annual forecasts (from the three models and the TFC) for the disaggregated series by purpose of travel. This figure highlights where the TFC seem to have been over-optimistic. For two of the four series, namely "VFR" and "Other", the forecasts produced by the models and the TFC are fairly similar (the exception being ETS for both cases which has a flat forecast function). However, there is a noticeable discrepancy between the models and the TFC forecasts for the other two series. The largest component of the total visitor nights is "Holiday" travel. Panel A highlights the significant divergence between the models and the TFC in the long term forecasts for this series. There is 
also a divergence between the models and the TFC forecasts for the "Business" component as shown in Panel C. The forecasts of these two components are the primary source of the overly optimistic TFC forecasts for total visitor nights.

PANEL A: Holiday

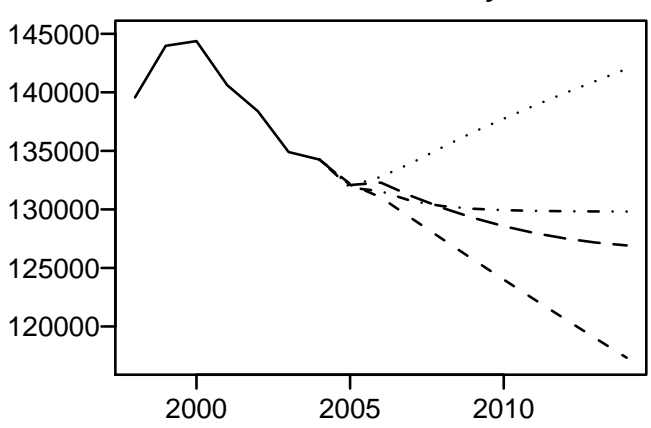

PANEL C: Business

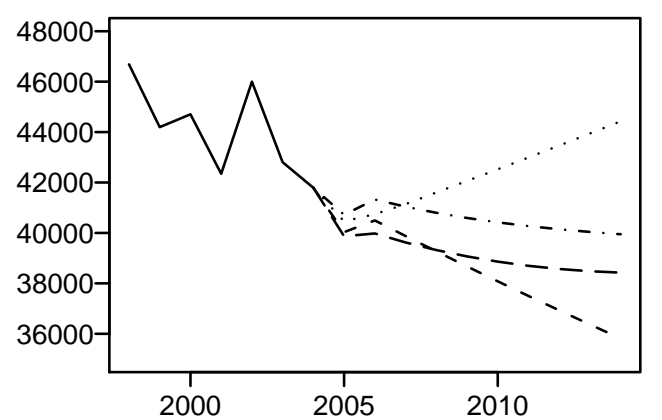

PANEL B: VFR

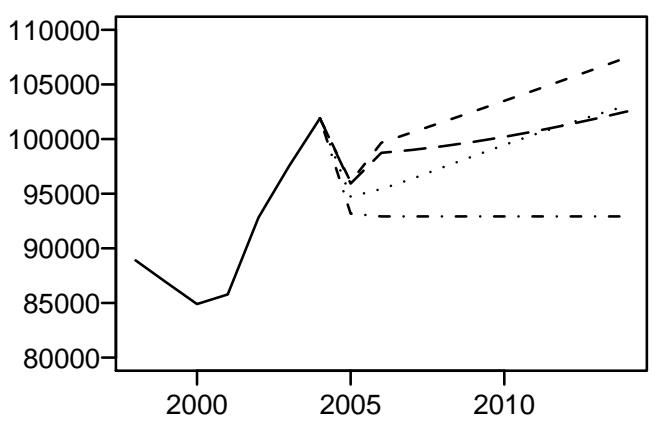

PANEL D: Other

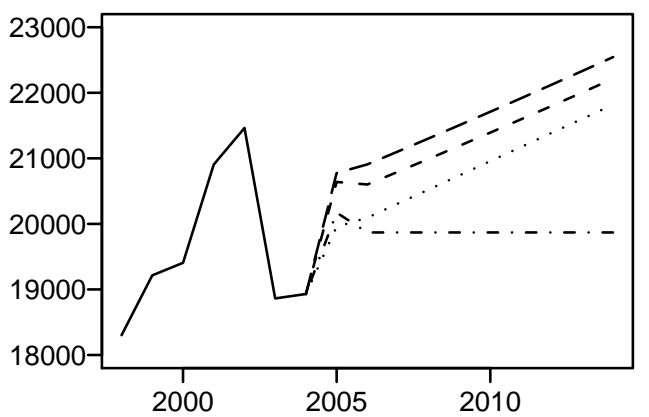

$$
\text { -. Regr ... ETS - ETSX … TFC }
$$

Figure 5: Long run annual forecasts for each of the four travel purpose components of visitor nights, from the three models and the TFC.

\section{Conclusion}

We have modelled Australian domestic tourism demand using three statistical models. The first approach used regression models. The estimated regression models have identified significant economic relationships for domestic tourism. This analysis has also highlighted the impact of world events on Australian domestic tourism such as the increase in business travel immediately after the 2000 Sydney Olympic games, and the significant increase in visiting friends and relatives after the 2002 Bali bombings. In order to take advantage of the time series properties of the data, we also consider time series modelling 
and implement innovation state space models (for the first time in the tourism literature). We combine the properties of the regression and the innovation state space models by proposing an innovation state space models with exogenous variables.

All three statistical models are shown to outperform the TFC published forecasts for short term demand of Australian domestic tourism. The long-term forecasts produced by the models indicate that the TFC long-term forecasts may be optimistic. In particular, the models suggest that TFC forecasts of the "Holiday" and "Business" travel components of Australian domestic tourism have been optimistic. The statistical models show that Australian domestic tourism is on the decline.

The proposed statistical models are clearly of substantial benefit to policy makers. In particular, we recommend the use of innovation state space models with exogenous variables (the ETSX models), which can capture time series dynamics as well as economic and other relationships, and which out-performed the other models based on both the MAE and MAPE error measures.

\section{Acknowledgments}

We would like to acknowledge the financial support of Tourism Research Australia and the Sustainable Tourism Cooperative Research Centre. We also thank Andrew Maurer and Tim Quinn at Tourism Research Australia for providing data, suggestions and explanations.

\section{References}

Aoki, M. (1987) State space modelling of time series, Springer-Verlag, Berlin.

Breusch, T. (1978) Testing for autocorrelation in dynamic linear models, Journal of Australian Economic Papers, 17, 334-355.

Brown, R. G. (1959) Statistical forecasting for inventory control, McGraw-Hill, New York.

Cho, V. (2003) A comparison of three different approaches to tourist arrival forecasting, Tourism Management, 24, 323-330. 
de Silva, A., R. J. Hyndman and R. D. Snyder (2006) The vector innovation structural time series framework: a simple approach to multivariate forecasting, Working paper, Department of Econometrics and Business Statistics, Monash University, Melbourne.

Dickey, D. A. and W. A. Fuller (1979) Distribution of the estimators for autoregressive time series with a unit root, Journal of the American Statistical Association, 74, 427-431.

Dickey, D. A. and W. A. Fuller (1981) Likelihood ratio statistics for autoregressive time series with a unit root, Econometrica, 49, 1057-1072.

du Preez, J. and S. F. Witt (2003) Univariate versus multivariate time series forecasting: an application to international tourism demand, International Journal of Forecasting, 19, 435-451.

Gardner, Jr, E. S. (1985) Exponential smoothing: the state of the art, Journal of Forecasting, 4, 1-28.

Gardner, Jr, E. S. and E. McKenzie (1985) Forecasting trends in time series, Management Science, 31(10), 1237-1246.

Godfrey, L. (1978) Testing for higher order serial correlation in regression equations when the regression contain lagged dependent variables, Econometrica, 46, 1303-1310.

González, P. and P. Moral (1995) An analysis of the international tourism demand of Spain, International Journal of Forecasting, 11, 233-251.

Green, W. H. (2000) Econometric Analysis, Prentice-Hall International, New Jersey, 4th ed.

Hannan, E. J. and M. Deistler (1988) The statistical theory of linear systems, John Wiley \& Sons, New York.

Harvey, A. C. (1990) Forecasting, Structural Times Series Models and the Kalman Filter, Cambridge University Press, Cambridge.

Holt, C. E. (1957) Forecasting seasonals and trends by exponentially weighted averages, O.N.R. Memorandum 52, Carnegie Institute of Technology, O.N.R. Memorandum Pittsburgh USA. Published in 2004 in the International Journal of Forecasting, 20, $1-13$, with additional commentaries. 
Hyndman, R. J. (2006) forecast: Forecasting time series, R package version 1.0. URL: http://www.robhyndman.info/Rlibrary/forecast

Hyndman, R. J., A. B. Koehler, J. K. Ord and R. D. Snyder (2005) Prediction intervals for exponential smoothing using two new classes of state space models, Journal of Forecasting, 24, 17-37.

Hyndman, R. J., A. B. Koehler, R. D. Snyder and S. Grose (2002) A state space framework for automatic forecasting using exponential smoothing methods, International Journal of Forecasting, 18, 439-454.

Jarque, C. and A. Bera (1980) Efficient tests for normality, homoskedasticity and serial independence of regression residuals., Economic Letters, 6, 255-259.

Kulendran, K. and M. L. King (1997) Forecasting international quarterly tourist flows using error-correction and time-series models, International Journal of Forecasting, 13, 319-327.

Kulendran, N. and S. F. Witt (2003) Forecasting the demand for international business tourism, Journal of Travel Research, 41, 265-271.

Kwiatkowski, D., P. C. B. Phillips, P. Schmidt and Y. Shin (1992) Testing the null hypothesis of stationarity against the alternative of a unit root: how sure are we that the economic time series have a unit root?, Journal of Econometrics, 54, 159-178.

Li, G., H. Song and S. F. Witt (2005) Recent developments in econometric modelling and forecasting, Journal of Travel Research, 44, 82-99.

Lim, C. and M. McAleer (2001) Cointegration analysis of quarterly tourism demand by Hong Kong and Singapore for Australia, Applied Economics, 33, 1599-1619.

Lim, C. and M. McAleer (2002) Time series forecasts of international travel demand for Australia, Tourism Management, 23, 389-396.

Makridakis, S., A. Anderson, R. Carbone, R. Fildes, M. Hibon, R. Lewandowski, J. Newton, E. Parzen and R. Winkler (1982) The accuracy of extrapolation (time series) methods: Results of a forecasting competition, Journal of Forecasting, 1, 111-153. 
Makridakis, S. and M. Hibon (2000) The M3-competition: Results, conclusions and implications, International Journal of Forecasting, 16, 451-476.

Makridakis, S., S. C. Wheelwright and R. J. Hyndman (1998) Forecasting: methods and applications, John Wiley \& Sons, New York, 3rd ed.

Morley, C. L. (1998) A dynamic international demand model, Annals of Tourism Research, $25,70-84$.

Morris, A., K. Wilson and A. Bakalis (1995) Modelling tourism flows from Europe to Australia, Tourism Economics, 1, 147-167.

$\mathrm{Ng}$, S. and P. Perron (2001) Lag length selection and the construction of unit root tests with good size and power, Econometrica, 69, 1519-1554.

Ord, J. K., A. B. Koehler and R. D. Snyder (1997) Estimation and prediction for a class of dynamic nonlinear statistical models, Journal of the American Statistical Association, 92, $1621-1629$.

Ord, J. K., R. D. Snyder, A. B. Koehler, R. J. Hyndman and M. Leeds (2005) Time series forecasting: The case for the single source of error state space, Working Paper 7/05.

Pegels, C. C. (1969) Exponential smoothing: some new variations, Management Science, 12, 311-315.

Ramsey, J. (1969) Test for specification errors in classical linear least squares regression analysis, Journal of the Royal Statistical Society B, 31, 350-371.

Snyder, R. D. (1985) Recursive estimation of dynamic linear models, Journal of the Royal Statistical Society B, 47, 272-276.

Tourism Forecasting Committee (2005) Tourism Forecasting Committee October 2005 Forecasts, Tourism Research Australia, Canberra.

Tourism Reseach Australia (2005) Travel by Australians, September Quarter 2005, Tourism Australia, Canberra.

Tourism White Paper (2003) A medium to long term strategy for tourism, Commonwealth of Australia. Available on www.industry.gov.au. 
Turner, L. W. and S. F. Witt (2001) Forecasting tourism using univariate and multivariate structural time series models, Tourism Economics, 7, 135-147.

White, H. (1980) A heteroskedasticity-consistent covariance matrix estimator and a direct test of heteroskedasticity, Econometrica, 48, 817-838.

Winters, P. R. (1960) Forecasting sales by exponentially weighted moving averages, Management Science, 6, 324-342.

Zellner, A. (1963) Estimators for seemingly unrelated regression equations: Some exact finite sample results, Journal of the American Statistical Association, 58, 977-992. 


\section{A Descriptions and projections of regressors}
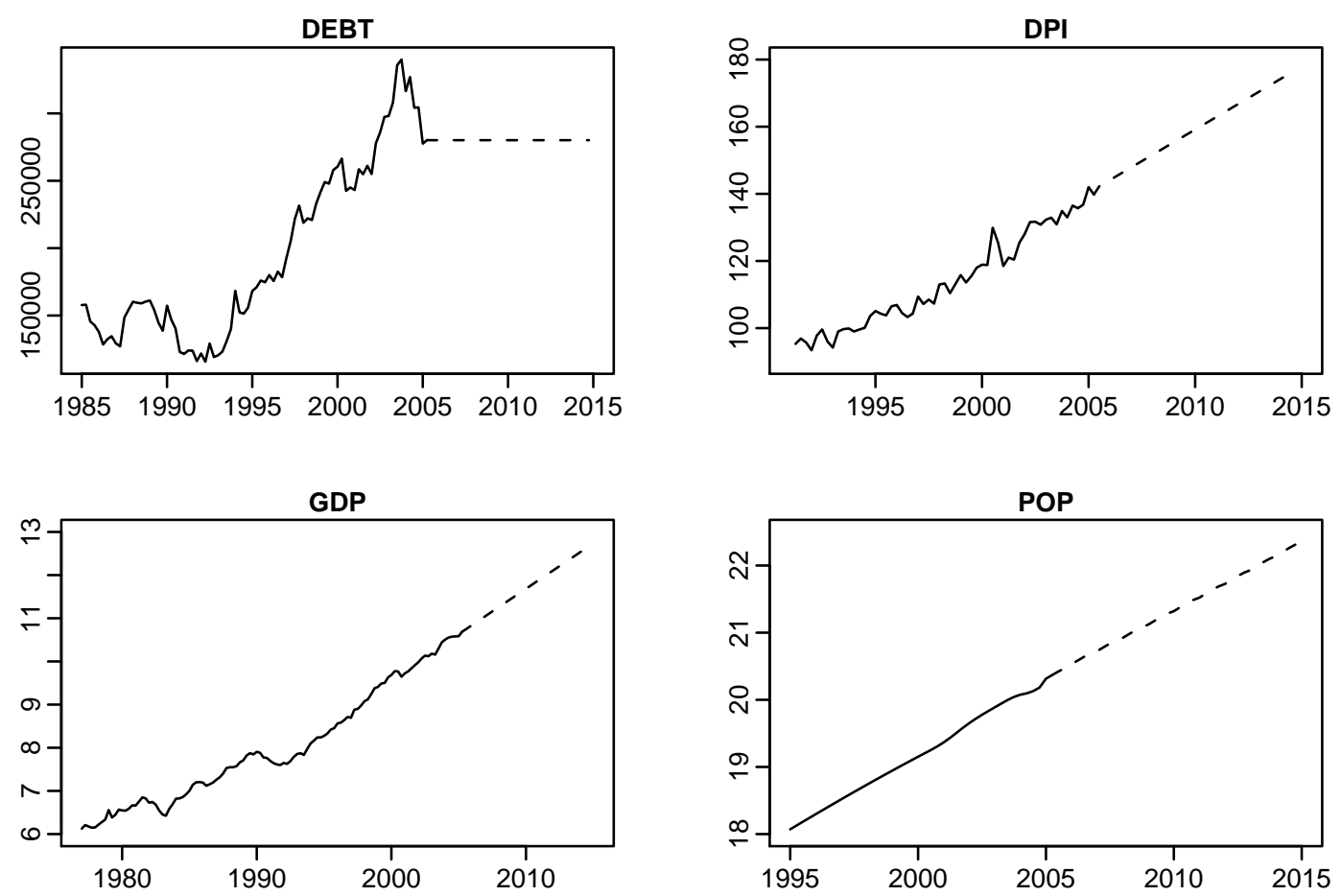

Figure 6: Levels of the regressors and their projections.

DEBT: Total real personal finance commitments per capita from all lenders in Australia in $\$ A$ thousands (seasonally adjusted, aggregated monthly series by averaging across the months of each quarter, series 5671-P1A from the DX database, Australia).

DPI: Domestic holiday travel and accommodation price index (seasonally adjusted by additive method, Australian Bureau of Statistics, series ID A2329356K).

GDP: Real Gross Domestic Product per capita in constant 03-04 \$A billions (seasonally adjusted, series AUS.EXPGDP.LNBQRSA from the DX database, Australia).

POP: Australian population and population projections as provided by the Australian Bureau of Statistics: Series B Population Projections, Australia 2004 to 2101, ABS cat. no. 3222.0

The forecasts for GDP, DPI and DEBT were produced using the R package "forecast" (Hyndman, 2006). The models selected by minimising the AIC are: additive trend, additive trend and no-trend, respectively. The forecasts for $P O P$ are the population projections 
supplied by the Australian Bureau of Statistics.

\section{B Visitor nights per capita series}

PANEL A

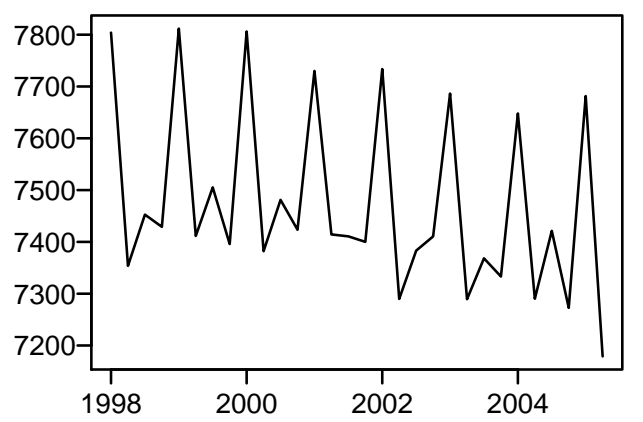

PANEL C

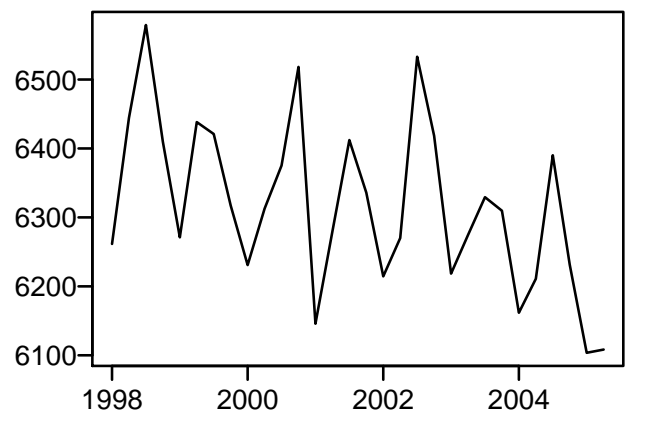

PANEL B

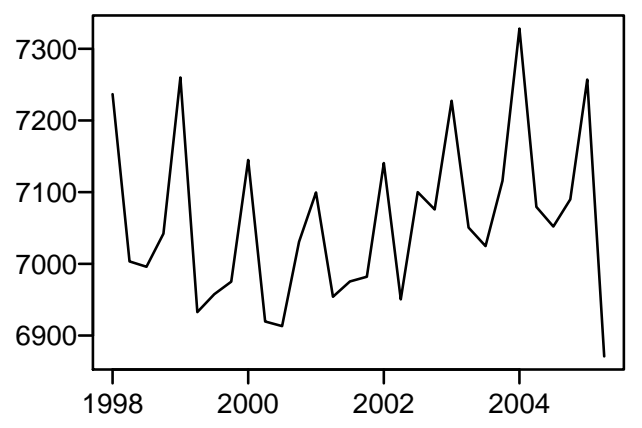

PANEL D

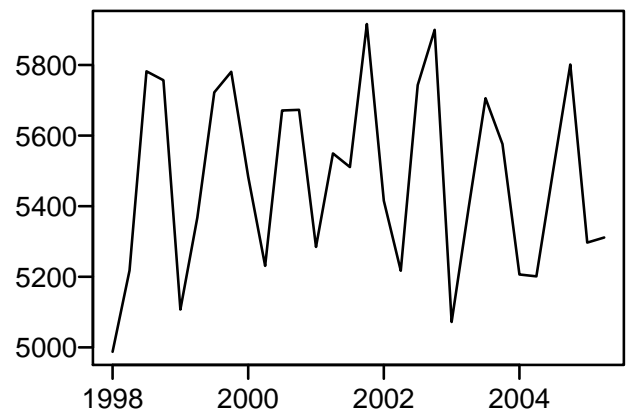

Figure 7: These are the visitor nights per capita series as defined in equation (3): PANEL A: $\ln V N_{t}^{H o l} \times 1000 ;$ PANEL B: $\ln V N_{t}^{V F R} \times 1000 ;$ PANEL C: $\ln V N_{t}^{B u s} \times 1000$; PANEL D: $\ln V N_{t}^{\text {Oth }} \times 1000$. 